\title{
Notas sobre la modernización del consumo en Asturias: almacenes textiles y bazares en Gijón y Oviedo (1874-1936)*
}

RESUMEN:

A través del presente artículo, apenas un esbozo trazado en el marco de una investigación en curso, nos proponemos ofrecer una serie de rasgos generales que nos permitan conocer mejor la rica realidad del comercio asturiano entre 1874 y 1936, fijando nuestra atención en las dos mayores poblaciones, Gijón y Oviedo. Intentaremos plasmar las principales características de algunos de los más importantes comercios de la época citada, valorando su arquitectura, diseño y configuración espacial, pero también estudiaremos otros elementos que nos permitirán detectar la decidida incorporación de ciertas novedades de la distribución y venta contemporáneas.

\section{PALABRAS CLAVE:}

Gijón, Oviedo, cultura del consumo, arquitectura comercial, bazares.

\section{ABSTRACT:}

This present paper, barely a sketched draft within an ongoing research, will explore a collection of general features that may allow us to know better the prosperous reality of the Asturian commercial sector between 1874-1936, putting the spotlight on its two biggest cities, Gijón and Oviedo. We will try to capture the main characteristics of some of the most important stores from the aforementioned period, analysing their architecture, design and spatial configuration, but we will also study other elements that will permit us to find the strong incorporation of some contemporary innovations concerning both distribution and sale.

\section{KEY WORDS:}

Gijón, Oviedo, consumer culture, retail architecture, bazaars.

Trabajo realizado al amparo de una ayuda FPU (ref. AP2012-2097, Ministerio de Educación, Cultura y Deporte) y elaborado dentro del Proyecto de Investigación "Espacios portuarios y villas costeras: modelos de estrategias urbanísticas y patrimoniales de regeneración y transformación del litoral asturiano" (ref. HAR2011-24464, Universidad de Oviedo, I.P.: $\mathrm{M}^{\mathrm{a}}$ Soledad Álvarez Martínez). Agradecemos a Ana Herrero, a Ma Jesús Villaverde y a José Luis Blanco el apoyo prestado durante el desarrollo de nuestra investigación. 


\section{Introducción}

Tal como han señalado Alonso y Conde, el modelo de sociedad de consumo típico del período contemporáneo se implantó en España con un notable retraso respecto a otros países, de una manera irregular y con peculiaridades, hasta el punto de que no suele hablarse de un verdadero boom consumista hasta la fase desarrollista del franquismo ${ }^{1}$. Sería equivocado, en cualquier caso, obviar que el avance del consumo como fenómeno cultural hegemónico se inició mucho tiempo antes: al menos desde el último tercio del s. XIX una parte de la sociedad urbana española, influida por las novedades puestas en práctica por los grands magasins franceses y los department stores anglo-americanos, iría acostumbrándose a las transformaciones que una porción creciente del sector comercial nacional incorporaría progresivamente a sus negocios y operaciones. Cuestiones que hoy damos por hechas, como el acceso libre, el precio fijo o la contemplación directa de los bienes de consumo, constituyeron en su momento innovaciones que transformaron la concepción del acto adquisitivo, a su vez mediatizado por el creciente poder de la propaganda y la mejora y embellecimiento de unos establecimientos convertidos en un mosaico social y de género ${ }^{2}$.

Entre la puesta en marcha de los pioneros Almacenes El Siglo de Barcelona (1881) ${ }^{3}$ y el estallido de la Guerra Civil en 1936, España experimentó un paulatino afianzamiento del nuevo espíritu consumista ${ }^{4}$ : este proceso resulta

\footnotetext{
Consúltese ALONSO BENITO, Luis Enrique y CONDE GUTIÉRREZ DEL ÁLAMO, Fernando, Historia del consumo en España: una aproximación a sus origenes y primer desarrollo, Debate, Madrid, 1994, especialmente el capítulo VI. Ver también CONDE GUTIÉRREZ DEL ÁLAMO, Fernando, "Notas sobre la génesis de la Sociedad de Consumo en España”, en Politica y Sociedad, Vol. 16 (Sociología del Consumo), Universidad Complutense de Madrid, 1994, pp. 135-148.

2 Un buen resumen en el capítulo "Shops and Shopping: the Department Store" de CORRIGAN, Peter, The Sociology of Consumption: An Introduction, SAGE Publications, London-Thousand Oaks, 1997, pp. 50-65. Ver igualmente WHITAKER, Jan, The Department Store. History, Design, Display, Thames \& Hudson, London, 2011.

3 Sobre El Siglo de Barcelona, ver CRUZ VALENCIANO, Jesús, El surgimiento de la cultura burguesa. Personas, hogares y ciudades en la España del siglo XIX, Siglo XXI de España Editores, Madrid, 2014, pp. 215-218.

4 Ver los capítulos VI, VII y VIII en RODRÍGUEZ MARTÍN, Nuria, La capital de un sueño. Madrid 19001936: la formación de una metrópoli europea, Tesis Doctoral, Universidad Complutense de Madrid, Madrid,
}

más que claro si contemplamos la abundancia, efervescencia y riqueza textual y gráfica de los anuncios de prensa publicados desde el arranque de la Restauración hasta el fin de la Segunda República. A lo largo del período comprendido entre 1874 y 1936, Asturias vivió un momento de pujanza comercial, agregando al panorama local no pocos cambios de carácter más o menos revolucionario: nuevas formas de venta y distribución, nuevos modos de presentación y exhibición de las mercancías, nuevos señuelos y técnicas de persuasión, etc. Desgraciadamente, las referencias bibliográficas específicas sobre la historia y desarrollo del comercio y la cultura del consumo en Asturias son claramente escasas, con honrosas excepciones 5 .

2013, disponible en: http://eprints.ucm.es/23049/1/ T34801.pdf [última consulta: 3-XII-2014; 18:14].

5 Para el período aquí abordado citaremos, por ser referencia fundamental, los trabajos que el historiador Francisco Erice ha dedicado a la burguesía industrial y comercial asturiana, y a los vínculos entre comerciantes y dependientes. ERICE SEBARES, Francisco, La burguesía industrial asturiana (1885-1920). Aproximación a su estudio, Silverio Cañada, Gijón, 1980; Propietarios, comerciantes e industriales. Burguesía y desarrollo capitalista en la Asturias del siglo XIX (1830-1885), Servicio de Publicaciones de la Universidad de Oviedo, Oviedo, 1995, dos tomos, y "Comercio, comerciantes y dependientes en Asturias (1885-1914). Notas sobre las actividades mercantiles en un ámbito regional de la España de entresiglos", en SEMATA, Ciencias Sociais e Humanidades, Vol. 12, Universidade de Santiago de Compostela, 2000, pp. 125162; en este último artículo, Erice señala: "La actividad mercantil y, más en concreto, la realidad social de los sectores en ella implicados (comerciantes y dependientes), no han gozado precisamente, en nuestro país, de la predilección de los historiadores" (p. 125). Igualmente véase TASCÓN FERNÁNDEZ, Luis Julio, "Industrias de bienes de consumo en Asturias, 1856-1973 (I)” en Historia de la Economía Asturiana, Editorial Prensa Asturiana, Oviedo, 1994, Vol. II, pp. 481-496. Para el caso gijonés ha de tenerse en cuenta la obra de GARCÍA QUIRÓS, Paz y FLORES SUÁREZ, José María, La ciudad del vapor. Historia de la industria y el comercio, GEA Distribuciones Gráficas, Gijón, 2000. Muy recientemente, el Ayuntamiento de Gijón ha promovido una publicación centrada en la historia del pequeño comercio de dicha ciudad. Ver ALONSO SUÁREZ, Carmen y RODRÍGUEZ FERNÁNDEZ DE LA VEGA, Pablo, El pequeño comercio en Gijón, Ayuntamiento de Gijón, Gijón, 2014. Dentro del ámbito particular de la historia del arte, el diseño y la publicidad, destacan el detallado trabajo de DÍAZ GONZÁLEZ, María del Mar, Asturias litografiada. El comercio y la industria en imágenes (1900-1970), Ediciones Trea, Cenero (Gijón), 2004, y el volumen de CAMPO FERNÁNDEZ, Misael, Cien años de publicidad en Asturias: 19012000, Cajastur, Oviedo, 2000. Mencionaremos el libro colectivo de GARCÍA LÓPEZ, José Ramón et al., Casa Masaveu: Oviedo, Fundación Dragados, Madrid, 2002. Algunos establecimientos son referidos en el capítulo de RODRÍGUEZ FERNÁNDEZ, Leire, “Creadores y difusores 

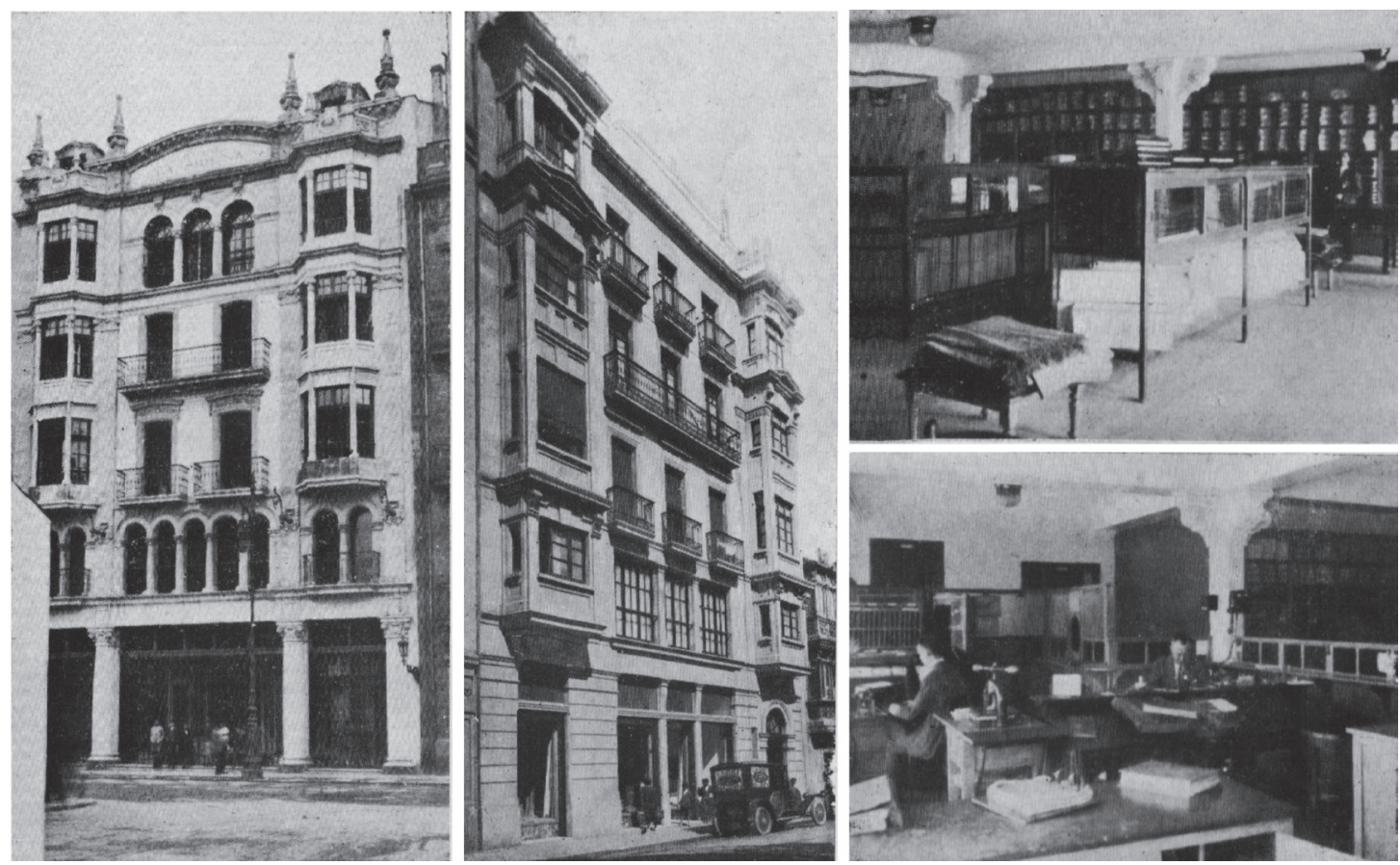

Fig. 1. Almacenes La Sirena (Gijón), obra de Manuel del Busto. De izquierda a derecha: fachada de Corrida, fachada de Pi y Margall -actual Moros- y dos vistas del interior. Fuente: Gijón Veraniego. 1925. Muséu del Pueblu d’Asturies.

El artículo que aquí presentamos no tiene otra pretensión más que la de esbozar, de forma sumaria y desde un planteamiento un tanto ecléctico, algunas ideas en torno a la modernización del consumo en el territorio asturiano durante el intervalo temporal citado, con la esperanza de que nuestras observaciones puedan ayudar a conocer mejor una parte de la vida cotidiana regional. Centraremos nuestro análisis en los dos principales núcleos urbanos de la provincia, Gijón y Oviedo, y prestaremos atención preferente a los establecimientos que, por su oferta comercial, consideramos más afines al espíritu del gran almacén por departamentos, pese a las evidentes y acusadísimas diferencias de escala, complejidad organizativa y volumen de ventas. En consecuencia, nos fijaremos en algunos de los almacenes de tejidos y bazares más significativos, sin ánimo de ofrecer un catálogo o relato total sino más bien una serie de impresiones ilustrativas.

del gusto en la decoración de interiores de la Asturias finisecular: industrias, talleres y casas comerciales" en FERNÁNDEZ GARCÍA, Ana María (coord.), Decoración de interiores. Firmas, casas comerciales y diseño en Asturias, 1880-1990, Septem Ediciones, Oviedo, 2012, pp. 13-54. Finalmente, señalaremos la obra de DEL CANO BARBÓN, Carlos, Historia del comercio y de los comerciantes de Oviedo, Trea, Somonte-Cenero (Gijón), 2014.

\section{El camino hacia la modernización} comercial tras las huellas del gran almacén: nuevas costumbres y nuevos espacios

En 1899, la Guía general del viajero en Asturias de Canella y Bellmunt afirmaba respecto a Oviedo: "El comercio ovetense alcanza gran desarrollo y goza de firme confianza, contando la capital con establecimientos y almacenes mercantiles de primer orden"6; ese mismo año, la villa de Gijón era descrita en otro volumen como "[...] una de las primeras poblaciones españolas en los órdenes industrial, mercantil y marítimo" . Ambos fragmentos dan cierta idea de una realidad sobre la que resultaría ocioso extenderse: la de la variedad y vitalidad del comercio minorista y mayorista en ambas poblaciones, que desde la década de 1880 harían gala de una tupida red de sociedades y establecimientos ampliamente glosada con periodici-

CANELLA SECADES, Fermín y BELLMUNT TRAVER, Octavio, Guía general del viajero en Asturias, con un Mapa de la provincia de Oviedo y láminas fototípicas y fotograbadas, Fototip. y Tip. 0. Bellmunt y C.a, Gijón, 1899, p. 77.

$7 \quad$ Nueva Guía de Gijón. Edición popular. Ilustrada con fotograbados, Imp. La Económica, Gijón, 1899, p. 3. 
dad en guías y anuarios ${ }^{8}$. La capital asturiana concentraba aún a finales del s. XIX una gran parte de sus mejores comercios en pleno casco antiguo, particularmente a ambos lados del eje formado por las calles Magdalena-Cimadevilla-Rúa, pero la apertura de la calle Fruela y su inmediata prolongación por Uría -incluyendo sus paralelas y transversales, como las calles Pelayo y Doctor Casal- ${ }^{9}$ causarian, a partir de 1890 y durante el primer tercio del s. XX, un importante desplazamiento de la actividad comercial a la nueva zona. En el caso gijonés, los espacios de consumo más distinguidos se repartían a finales del s. XIX entre las inmediaciones del puerto local -Trinidad, San Antonio y Cuatro Cantones- y las calle Corrida y San Bernardo con sus perpendiculares; desde 1900 en adelante, dichas travesías y otras tantas -Jovellanos, Moros, Munuza- acapararían el protagonismo mercantil, pero la actividad también se extendería hacia áreas algo más apartadas como la plaza de San Miguel ${ }^{10}$.

Los grandes almacenes extranjeros y nacionales fueron bien conocidos en Asturias a partir de $1880^{11}$, y sin duda se convirtie-

8 Sirvan como ejemplo las siguientes obras: CARTAVIO, Ángel Román, Guía industrial y comercial de Asturias, Imp. de Vallina y Compañía, Oviedo, 1884; GARCÍA BOSQUET, José, Guía de Gijón. Datos exactos de todo lo concerniente a esta Villa, Monumentos, Industrias, Artes, Comercio, Dependencias del Estado, Servicios Públicos, Festejos, etc., Imp. de A. Carreño, Gijón, 1891; Álbum Anunciador 1893: Asturias, Luarca-Imp. La Económica, 1893; Nueva Guía de Gijón, opus cit.; GUTIÉRREZ MAYO, José y ÁLVAREZ URÍA, Gerardo, Guía general de Asturias, Compañía Asturiana de Artes Gráficas, Gijón, 1904 (año II) y 1905 (año III); NAVA VALDÉS, Antonio, Turismo Asturias (Guía para el turista), Talleres Gráficos de Ramiro P. del Río e Hijo, Luarca, 1914. Mención aparte merecerían los numerosos portfolios y programas de fiestas existentes.

9 La explicación más completa sobre esta cuestión se encuentra en TOMÉ FERNÁNDEZ, Sergio, Oviedo. La formación de la ciudad burguesa. 1850-1950, Colegio Oficial de Arquitectos de Asturias, Oviedo, 1988.

10 Sobre el crecimiento urbano de Gijón, ver LLORDÉN MIÑAMBRES, Moisés, Desarrollo económico y urbano de Gijón. Siglos XIX y XX, Servicio de Publicaciones de la Universidad de Oviedo, Oviedo, 1994.

11 Los reconocidos grandes almacenes Printemps de París se anunciaban con cierta frecuencia en la prensa periódica asturiana, ofreciendo a los interesados el envío gratuito de sus álbumes ilustrados -plagados de grabados con las últimas novedades en moda y tejidos- y de muestras de géneros. Ver anuncios en $\mathrm{El}$ Carbayón, Oviedo, 14-III-1887 y El Correo de Asturias, Oviedo, 25-III-1900. El periódico editado por los grandes almacenes El Siglo de Barcelona era igualmente conocido, como se puede ver en El Carbayón, Oviedo, 7-V-1885 y 1-VI-1885. Dicha compañía en- ron en un referente y una aspiración para los principales empresarios locales; numerosos testimonios evidencian el deseo de los comerciantes por inscribir sus negocios, más o menos sencillos, en la nueva oleada de modernidad que bullía en las capitales españolas y más allá de nuestras fronteras. Dicha entrada en la vanguardia y el progreso comercial se produciría, por una parte, a través de la puesta en práctica de las anteriormente mencionadas reformas relacionadas con el desenvolvimiento mercantil. En este sentido, sabemos que la práctica del precio fijo -que implicaba, por extensión, la erradicación del regateo- ya era llevada a cabo en Asturias por el reputado y descollante comercio de Pedro Masaveu Rovira en una fecha tan precoz como $1872^{12}$; llegado el año 1900 , los Almacenes Al Pelayo de Oviedo convencían a la clientela afirmando que "Marcadas las prendas con su valor, es el mejor sistema para que todos compren igual" ${ }^{13}$, y en 1909 los productos etiquetados y el rigor en las cifras servían de reclamo a los recién llegados Almacenes El Águila de Gijón ${ }^{14}$, lo que nos

viaba viajantes a Gijón y Oviedo para enseñar muestrarios, catálogos y fotografías de los géneros a su potencial clientela. Las demostraciones se producian en el lugar donde se hospedaba el viajante -así ocurría, por ejemplo, en el Hotel Malet de Gijón y en el Hotel Francés de Oviedo- aunque previo aviso también se pasaba el muestrario a domicilio. Ver anuncios en $\mathrm{El}$ Noroeste, Gijón, 2-XI-1905 y El Correo de Asturias, Oviedo, 17-X-1911. Sobre la presencia de viajantes en hoteles asturianos ofrece más datos SUÁREZ BOTAS, Gracia, Hoteles de viajeros en Asturias, KRK Ediciones, Oviedo, 2006, pp. 307, 312 y 352. A todo esto hemos de sumar el hecho de que los comerciantes de mayor rango viajaban con regularidad a Madrid, Barcelona y distintas capitales de Europa para adquirir mercancías y traer a Asturias las últimas novedades, periplos durante los cuales sin duda conocerían las flamantes "catedrales del consumo".

12 Así se puede comprobar en una factura con fecha 20 de agosto de 1872 emitida por el establecimiento de novedades de Pedro Masaveu y Compa , perteneciente al Archivo Histórico de Asturiana de Zinc y reproducida en el capítulo de GARCÍA LÓPEZ, José Ramón, "La Casa Masaveu: el triunfo de la laboriosidad", en GARCÍA LÓPEZ, José Ramón et al., Casa Masaveu, opus cit., p. 18. Este autor señala que "[...] la actuación innovadora de Casa Masaveu no se limitó a la distribución de las mercancías más modernas, sino a la propia técnica comercial: se incorporó como slogan definitorio la norma del precio fijo , símbolo de seriedad y garantía por contraposición al tradicional regateo, que todavía imperaba en la generalidad del comercio". Ibídem, p. 15.

13 Ver anuncio en El Carbayón, Oviedo, 2-X-1900.

14 "Hoy apertura de los grandes almacenes de ropas confeccionadas El Águila [...] Precio fijo. Todos los artículos 

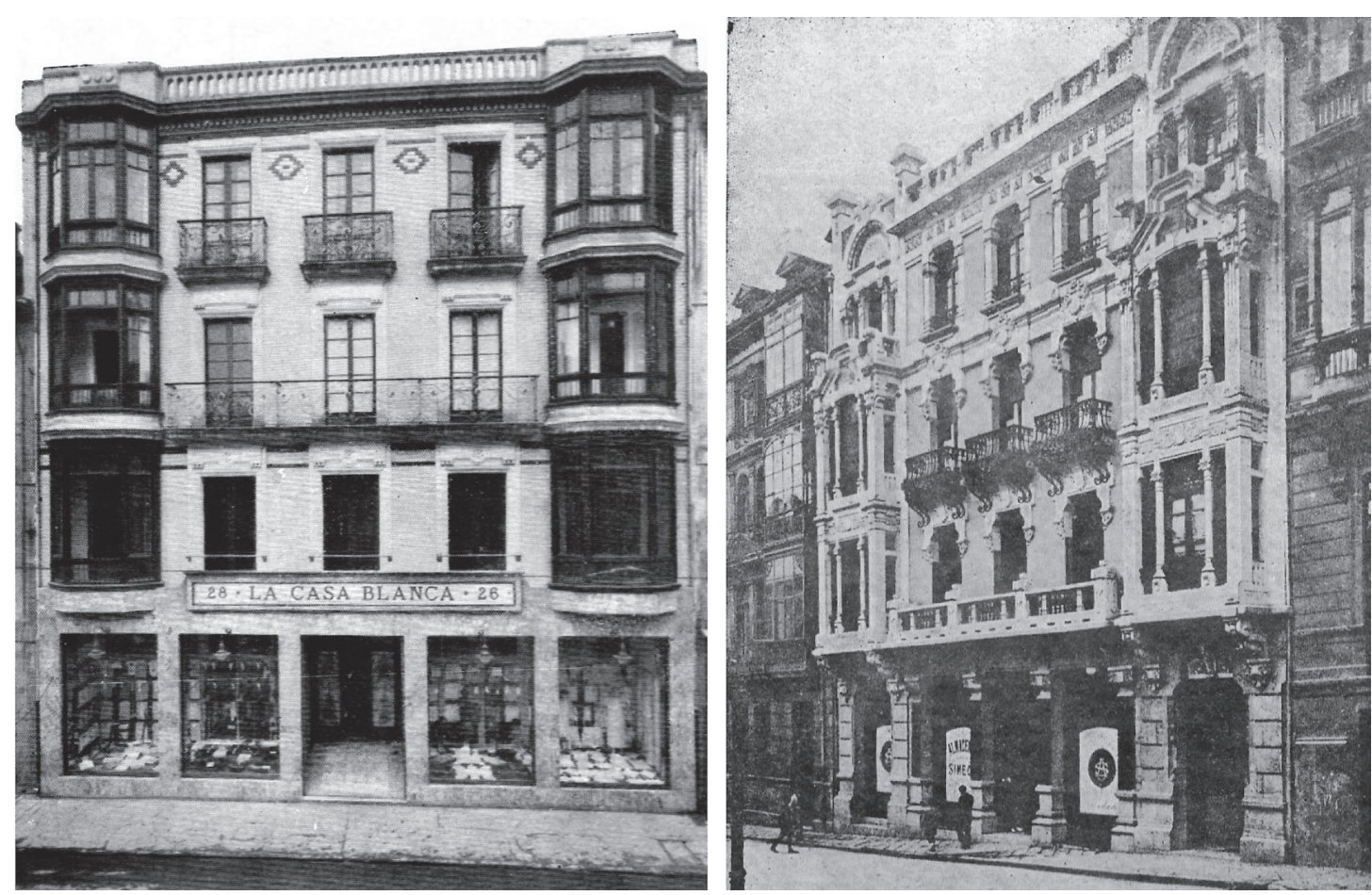

Fig. 2. Izquierda: La Casa Blanca (Gijón), tras la reforma de Mariano Marín Magallón. Fuente: Deporte y Turismo Astur. Verano de 1925. Biblioteca de Asturias. Derecha: Casa Simeón (Oviedo), obra de Julio Galán Carvajal. Fuente: Álbum Gutenberg: septiembre de 1920. Biblioteca de Asturias.

permite sospechar que dichos procedimientos tardaron tiempo en asentarse y normalizarse como hábito comercial. Prueba de ello es que en un momento tan sumamente tardío como 1924, los almacenes gijoneses La Ciudad de Londres seguían incluyendo en sus anuncios este método ${ }^{15}$.

Otro ejemplo elocuente de los cambios en ciernes lo hallamos en un anuncio del ovetense Bazar Inglés, situado en la esquina entre las calles Rúa y Platería, que en 1891 destacaba la "entrada libre" y los "precios fijos", para a continuación explicar: "Las grandes reformas introducidas recientemente en este Establecimiento, planteando el nuevo sistema de los mejores Bazares de PARÍS y MADRID, permiten al público la libre entrada y el examinar, al primer golpe de vista, lo más rico y nuevo de sus secciones [...]"16. Aunque con toda seguridad el citado bazar distaba mucho de asemejarse a los refinados magasins franceses, es

llevan los precios marcados en las respectivas etiquetas. Entrada libre [...]". El Noroeste, Gijón, 29-IV-1909.

15 Ver publicidad en El Noroeste, Gijón, 2-I-1924.

16 Anuncio recogido en CABALLERO, Ricardo y PALACIOS SUÁREZ, Miguel, Guía ilustrada del viajero en Gijón, Imp. del Comercio, Gijón, 1891, p. XXII. importante destacar la división de su oferta en departamentos muy rudimentarios, así como el manifiesto esfuerzo por mejorar las técnicas de exposición y venta para favorecer, frente a la ocultación, el escamoteo y demás tretas frecuentes, una nueva relación de los clientes con los productos más directa y sensitiva, a imitación de los grandes almacenes.

A la actualización de los sistemas de venta y la replanteada disposición de los bienes de consumo habría que añadir, dentro del proceso de transformación del comercio urbano asturiano, el crucial papel jugado por el espacio, entendiendo como tal la arquitectura, las instalaciones mobiliarias, la decoración y por supuesto, los escaparates. Todas estas cualidades materiales, debidamente implementadas, constituirían un reflejo directo y expresivo de la fuerza, modernidad y capacidad del comercio asturiano para medirse con las principales ciudades españolas y extranjeras. El miedo al fracaso o a la pérdida del favor del público a causa de la obsolescencia de las instalaciones será un fantasma que desde estos momentos persiga a buena parte de los empresarios. En 1890, el ovetense comercio de novedades Los Chicos -que previamente había estado ubica- 


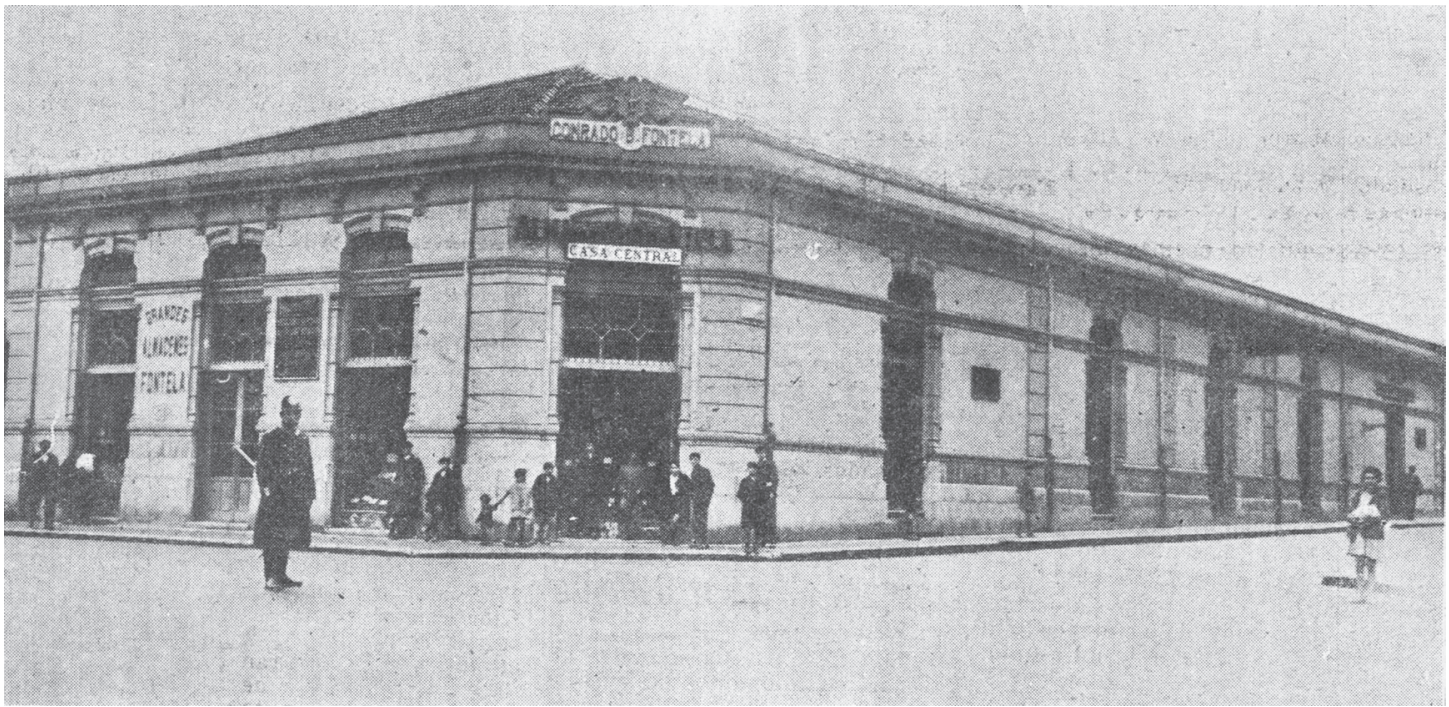

Fig. 3. Almacenes Fontela (Oviedo) en la calle Doctor Casal. Edificio para almacén según proyecto de Ulpiano Muñoz Zapata. Fotografía extraída de un anuncio de 1928. Fuente: diario Región, Oviedo, 3-I-1928. Real Instituto de Estudios Asturianos.

do en las calles Rúa (1881-1886) y Altamirano (1886-1890)- ${ }^{17}$ estrenaba su tercera y definitiva sede en los amplios y suntuosos bajos de la casa $n^{\circ} 1$ de la calle Fruela en su esquina con Rosal, en un local, según recogía El Correo de Asturias, "[...] propio para comercios de primer orden, y montado con todo el lujo que exige la vida moderna" ${ }^{18}$; dicho negocio retomaría el impulso renovador tiempo después, anunciando en 1914 " [...] la reforma del local, para su transformación en grandes almacenes al estilo de las más importantes capitales [...]" ${ }^{19}$. Mantener la tienda actualizada requería constantes esfuerzos, tal como explica una crónica de 1915 acerca de la acreditada sede gijonesa de la Casa Masaveu: "Podía Masaveu dormirse sobre los laureles de su fama; pero con la mira puesta en el avance y en la complacencia al público, acometió unas costosísimas reformas que le colocan al nivel de los de más rumbo nacional" ${ }^{20}$. Equipararse comercialmente a Madrid o a Barcelona llegó a constituir una aspiración casi obsesiva, recogida constantemente en la prensa y publicidad del período: como muestra, una breve reseña de 1902 referida al célebre comercio de tejidos y modas Al San Luis -situado en el encuentro de las calles Altamirano y Rúa de Oviedo y funda-

17 Noticias sobre las anteriores aperturas de Los Chicos en El Carbayón, Oviedo, 4-I-1881 y 29-III-1886.

18 El Correo de Asturias, Oviedo, 14-V-1890.

19 El Carbayón, Oviedo, 1-I-1914.

20 Recogido en Gijón Veraniego. 1915, Talleres Tipográficos La Fe, Vega y Bonet, Gijón, 1915. do en $1882-^{21}$ concluía de la siguiente forma: "Nos complace ver el desarrollo de nuestro comercio ovetense que puede hoy rivalizar en surtidos y elementos con los más notables de Madrid y Barcelona"22. Pasado el tiempo, todavía en la década de 1920 persistía el manejo de este tópico por parte de los Almacenes La Sirena en Gijón ${ }^{23}$ y los Almacenes de Julio Fontela en Oviedo ${ }^{24}$.

Ya hemos hecho referencia a la figura de Pedro Masaveu Rovira, cuyo comercio de tejidos llegaría a convertirse, en palabras de García López, en "[...] establecimiento líder del comercio ovetense [...]", manteniendo fructíferos contactos con Francia y las Islas Bri-

21 "Otro sí: se ha inaugurado en esta capital un magnífico comercio de modas para señoras, sastrería y camisería que se titula "Al San Luis"; y también los jóvenes $\mathrm{Pu}$ jalte, Aza y Campomanes, que con tan buenos ánimos y disposiciones emprenden sus tareas comerciales, merecen de mi parte los mejores deseos". En Revista de Asturias, Imp. y Lit. de Vicente Brid, Oviedo, Año VI, Núm. 7, 15-IV-1882, p. 112.

22 El Progreso de Asturias, Oviedo, 8-IV-1902.

${ }^{23}$ En 1920 un folleto explicaba las obras de construcción de un nuevo edificio para dichos almacenes llamado a albergar "[...] un establecimiento modelo, al estilo de las grandes poblaciones, como los que funcionan en Madrid y Barcelona”. En Gijón Veraniego. 1920, Vega y Bonet, Año VII, 1920.

24 "Almacenes Julio Fontela. Uría, 42. ¡Oviedo, a la altura de Madrid! Estos ALMACENES, han sufrido en estos últimos meses una enorme transformación, hecha con el objeto de ponerse a la altura de los grandes almacenes de MADRID, BARCELONA, etc.”. Anuncio en El Carbayón, Oviedo, 30-XII-1928. 
tánicas ${ }^{25}$ : por encargo de dicho industrial, el arquitecto Javier Aguirre Iturralde proyectaría en 1882 un magnífico edificio de carácter clasicista isabelino ${ }^{26}$, solemnemente inaugurado la noche del viernes, 18 de septiembre de 1885, meses después del fallecimiento del promotor ${ }^{27}$. Los salones de sus distintas plantas albergaron un espacioso almacén de tejidos y modas, una sección de banca, la vivienda de la propia familia Masaveu y, en el último piso, alojamiento para los empleados solteros $^{28}$. La obra, de considerables dimensiones y cuidada estética, planteaba ya un ambicioso modelo de comercio monumental que pasado el tiempo se vería complementado con el Gran Salón Bazar Masaveu, sobre el que más adelante aportaremos algunos datos.

25 Ver GARCÍA LÓPEZ, José Ramón, “La Casa Masaveu: el triunfo de la laboriosidad", opus cit., pp. 13-15.

26 Ver MORALES SARO, M Cruz, Oviedo: arquitectura $y$ desarrollo urbano. Del Eclecticismo al Movimiento Moderno, Servicio de Publicaciones de la Universidad de Oviedo, Oviedo, 1981, pp. 68-69 y más recientemente, de la misma autora: "La Casa Masaveu y el arquitecto Javier Aguirre”, en GARCÍA LÓPEZ, José Ramón et al., Casa Masaveu, opus cit., pp. 70-81.

27 "El Nuevo Establecimiento de los Sres. Masaveu y C. ${ }^{\text {. }}$ La inauguración del nuevo establecimiento de los Sres. Masaveu y Compañía fue un verdadero acontecimiento en Oviedo. El suceso nada tuvo de fastuoso: fué en silencio, y bien adivinarán la causa los que recuerden el reciente fallecimiento del jefe y fundador de la casa. $\mathrm{Al}$ oscurecer de ayer viernes, apareció el nuevo comercio abierto y expléndidamente alumbrado [...] Oviedo cuenta con un elegante edificio más, y con una instalación comercial á la altura de las similares de las más grandes capitales". Ver crónica completa en El Carbayón, Oviedo, 19-IX-1885.

28 Datos aportados por GARCÍA LÓPEZ, José Ramón, "La Casa Masaveu: el triunfo de la laboriosidad", opus cit., p. 24. Es bien sabido que tradicionalmente los comerciantes proporcionaban a sus dependientes alojamiento -muchas veces en la propia tienda-, costumbre paternalista y mecanismo de control que los grandes almacenes ampliarían creando verdaderos complejos residenciales para sus trabajadores, con estrictas normas. Ver HOSGO0D, Christopher P., "Mercantile Monasteries: Shops, Shop Assistants, and Shop Life in Late-Victorian and Edwardian Britain", en Journal of British Studies, Vol. 38, No. 3, Masculinity and the Lower Middle Class, Cambridge University Press-NACBS, July 1999, pp. 322-352. Véase igualmente MCBRIDE, Theresa M., “A Woman's World: Department Stores and the Evolution of Women's Employment, 1870-1920", en French Historical Studies, Vol. 10, No. 4, Duke University Press, Autumn 1978, pp. 664-683, especialmente las pp. 671-673, donde se describen las condiciones de vida de las empleadas alojadas en las dependencias ofrecidas por ciertos almacenes franceses como el Bon Marché y el Louvre.
Décadas más tarde, en abril de 1924, la ciudad de Gijón asistía a la inauguración del nuevo edificio de Almacenes La Sirena, una sólida obra de Manuel del Busto resultante de la reforma y ampliación de una construcción anterior, con fachada a las calles Corrida y Moros, varios pisos de viviendas y dos generosas plantas destinadas a almacén textil, unidas entre sí por un ascensor al servicio de la clientela, una absoluta novedad de tono cosmopolita ${ }^{29}$. En el lado de Corrida, los escaparates de La Sirena, tendidos en el basamento entre potentes pilastras y columnas de orden clásico, transmitían al público la idea de un verdadero templo del comercio. Ante dicha apertura la prensa regional se deshizo en elogios, llegando a describir las instalaciones comerciales como "[...] un amplio local, rebosante de luz y con todo el estilo de los grandes almacenes modernos" ${ }^{30}$; un despliegue de tal calibre dejaba fuera de toda duda la capacidad del sector mercantil asturiano para alcanzar la dignidad tantas veces pretendida. Otro comercio gijonés que en 1924 exhibía magníficas dependencias era La Casa Blanca, ubicado en la calle de los Moros -entonces Pi y Margall, n 26-28- y caracterizado por la venta de ropas de dicho color. El negocio, regentado por los señores Argüelles y Matos, se situaba en un bloque de varias plantas reformado ex profeso para su función comercial según proyecto de obra autorizado por Mariano Marín Magallón ${ }^{31}$. La tienda se ubicaba en el bajo a

29 Proyecto y tramitación (agosto-septiembre de 1919) disponibles en el Archivo Municipal de Gijón (AMG), expediente 225/1919. El edificio ha sido brevemente comentado por BLANCO GONZÁLEZ, Héctor, El Gijón de Manuel del Busto. Guía de arquitectura, Ateneo Obrero de Gijón, Gijón, 2000, pp. 58-59. Sobre el ascensor: "Para el servicio del público y proporcionarle las mayores comodidades, un magnífico ascensor lleva a los clientes desde la planta baja al entresuelo, ascensor que también sirve para el resto del edificio". En $L a$ Prensa, Gijón, 20-IV-1924.

30 Región, Oviedo, 20-IV-1924. Tras la inauguración de la nueva casa, los Almacenes La Sirena proyectarían con intensidad y confianza una imagen de grandes almacenes al modo extranjero, tal como se puede ver en los números de El Noroeste, Gijón, días 15-VIII-1924, 16-VIII-1925 y 25-VIII-1926.

31 En 1921, La Casa Blanca se situaba en el $n^{\circ} 28$ de la calle Moros; en agosto de ese mismo año, un periódico local explicaba que los Sres. Argüelles y Matos, “[...] con el fin de aumentar todas las secciones y montarlas a la altura de los grandes comercios europeos, han adquirido la casa contigua, número 26, donde en breve se proponen ejecutar grandes reformas, instalando unos grandes talleres de confección, que han de ser la admiración de cuantos se interesan por el progreso de 
pie de calle, y los talleres de confección en el primer piso; cuatro magníficos paños de escaparate cuadrangulares flanqueaban la entrada, ensalzados como un "[...] dechado de buen gusto, delicadeza y variedad en toda ocasión, y frente á los cuales se detienen irremisiblemente cuantos por allí pasan, atraídos por la sencillez y la armonía que en ellos impera" ${ }^{32}$.

En ocasiones, reconocidas cadenas españolas intervinieron en la actualización del paisaje comercial regional. Tal fue el caso de los Almacenes Simeón, emporio de origen gallego destinado a la venta de tejidos y novedades, que llegaría a contar con tiendas en Oviedo y Gijón. En la capital asturiana, la compañía iniciaría sus operaciones en un local en la calle Magdalena ${ }^{33}$, pero posteriormente trasladaría su sede al $n^{\circ} 4$ de la calle San Francisco, ocupando la tienda la extensa planta baja -más de veinte metros de profundidad por unos doce de ancho- de un edificio residencial promovido por la propia empresa y firmado en 1915 por Julio Galán Carvajal $^{34}$, contando además con un

esta villa”. El Noroeste, Gijón, 14-VIII-1921. Tres años después, el mismo diario relataba: "Una entidad para cuyos almacenes y talleres de confección de ropa blanca ha habido necesidad de construir un edificio tan suntuoso y amplio como el que representa la fotografía que acompaña á esta información, es algo que tiene una personalidad propia bien definida y que caracteriza, no sólo el relieve mercantil de sus dueños, sino la localidad en que radica”. El Noroeste, Gijón, 15-VIII1924. En realidad, lo que se hizo fue remodelar los números 26-28 de la calle Moros, unificándolos mediante cambios en los interiores y la fachada: "Don Francisco Matos Dávila, vecino de esta villa [...] en representación de la Sociedad comercial "Argüelles y Matos" de Gijón y de la Sra. Dña. María de la Concepción Castillo de Argüelles [...] expone: que conviniendo á sus representados hacer obras de reforma en las casas de la calle de Pi y Margall no 26 y 28, propiedades de dicha sociedad y señora respectivamente, conforme á la adjunta memoria explicativa y planos de obra que autoriza el Arquitecto Don Mariano Marín y Magallón [...] solicita de V.S. la oportuna licencia para verificar dichas obras de reforma [...]". En AMG, expediente 32/1922.

32 Ver reportaje en El Noroeste, Gijón, 15-VIII-1924.

33 "Bajo la razón social de Viuda e Hijos de Simeón García y $\mathrm{C}^{\mathrm{a}}$, se ha establecido en el amplio local de la casa llamada de Vistalegre, calle de la Magdalena, un gran almacén de toda clase de tejidos. Dicho establecimiento estará a cargo de D. Manuel y D. Vicente Rubio de la Riva, quienes también han otorgado poderes generales a D. Félix Miguel Martínez. Deseamos a los dueños del mencionado establecimiento toda clase de prosperidades en el negocio que han emprendido". El Correo de Asturias, Oviedo, 3-I-1900.

34 El permiso de construcción lo solicita Manuel Rubio, representante de la sociedad Hijos de Simeón García. Tramitación y proyecto disponibles en el Archivo importante almacén-depósito de mercancías en la parte posterior del bloque; el conjunto sería gravemente dañado en la Revolución de 0ctubre de 1934, y reconstruido posteriormente, durante un período de penosas circunstancias. ${ }^{35}$ Por su parte, los ya citados Almacenes El Águila sumaron, con su llegada a Gijón, una tienda más a su lista de sucursales por España, que en 1909 superaba la docena ${ }^{36}$.

Una variante peculiar dentro de la realidad comercial aquí tratada la conforman los establecimientos que podríamos llamar de planta $b_{a j a}{ }^{37}$, con desarrollo eminentemente horizontal y en ocasiones cierto carácter insular. En Oviedo destacó el elegante anexo en estilo ecléctico-modernista que Juan Miguel de la Guardia concibió en diciembre de 1899 para

Municipal de Oviedo (AM0), 1-1-64-76. Se conserva abundante documentación complementaria referente a este proyecto en el Archivo de Julio Galán Carvajal, actualmente depositado en el Museo de Bellas Artes de Asturias, caja 16, año 1915. Dicho arquitecto puso gran empeño en la concepción de elementos ornamentales como cancelas, puertas y balcones, diseñando igualmente unas bellas estanterías para el almacén de los Hijos de Simeón García, de apoyo sobre pared, con doble altura y corredor elevado, finos balaustres y motivos en forma de S. En opinión de $\mathrm{M}^{\mathrm{a}}$ Cruz Morales, en este edificio "se sintetizan en el exterior las formas sinuosas de recuerdo modernista con repertorio ornamental más académico”. Cita extraída de MORALES SARO, Ma Cruz, “Julio Galán Carvajal”, en FEÁS COSTILLA, Luis (coord.), Artistas asturianos. Tomo X: Arquitectos, Hércules Astur, Oviedo, 2007, p. 291.

35 Sobre la destrucción de los Almacenes Simeón en 0ctubre del 34 véase por ejemplo el reportaje recogido en $\mathrm{La}$ Voz, Madrid, 17-X-1934. En 1935 se inició la reconstrucción del conjunto, como puede comprobarse en el expediente conservado en AM0, 41/35. Debido al inmediato estallido y desarrollo de la Guerra Civil, las obras se detendrían, retomándose en 1940. Ver explicación en AMO, expediente 145/40.

36 Concretamente, tenían sedes en Madrid, Barcelona, Alicante, Bilbao, Cádiz, Cartagena, Málaga, Palma de Mallorca, Santander, Sevilla, Valencia, Valladolid y Zaragoza. Ver anuncio en El Noroeste, Gijón, 29-IV-1909.

37 Los almacenes que así denominamos podian presentar interiormente una compartimentación en varios niveles mediante escaleras, tarimas, barandillas y pasos elevados, pero al exterior manifestaban una única planta a ras de suelo. Un buen ejemplo de este tipo de construcción lo constituía el almacén de harinas y coloniales de Luis y Celestino Rodríguez en la calle Campoamor de Oviedo, que citamos por su calidad modernista con acusados rasgos vieneses. El proyecto, de Emilio Fernández Peña (1907), se conserva en AMO, 1-1-11-37. El almacén, construido con mínimos cambios respecto al plan inicial, aparece reproducido en el Programa Oficial del Ayuntamiento de Oviedo, Festejos de San Mateo, septiembre de 1910, Tip. de Uría Hnos., Oviedo, 1910. 

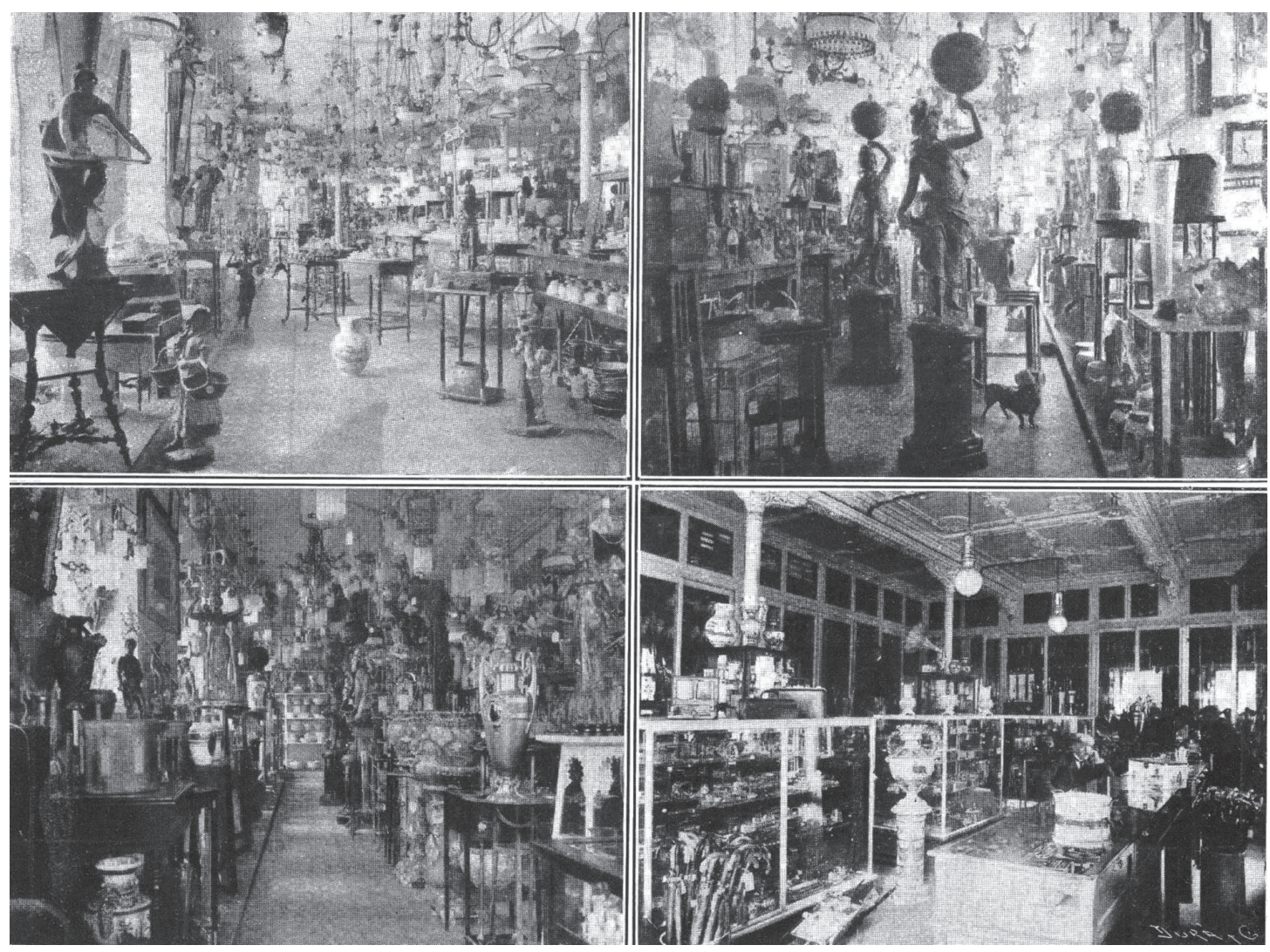

Fig. 4. Novedades Benigno Piquero y Cía. (Gijón). Fuente: Centenario de Jovellanos. Gijón. 1911. Muséu del Pueblu d’Asturies.

Juan Botas Roldán a modo de complemento a la casa-almacén familiar en la calle Martínez Marina, conjunto que hoy pervive muy reformado $^{38}$. En la misma ciudad, por encargo de los Sobrinos de Fontela, Ulpiano Muñoz Zapata firmó en diciembre de 1915 el proyecto de un imponente almacén entre las calles Portugalete -actual Melquíades Álvarez- y Doctor Casal $^{39}$ : la obra, que no se conserva, era una

38 El diseño de Juan Miguel de la Guardia se conserva en AMO, 1-1-38-21. Este almacén de tono palaciego es comentado por GONZÁLEZ ROMERO, José Fernando, Arquitectura industrial de Oviedo y su área de influencia. Una realidad dúplice, Trea, Cenero (Gijón), 2011, pp. 101-102. Sobre la historia empresarial y evolución arquitectónica de los Almacenes Botas durante los siglos XIX y XX, véase RODRÍGUEZ-VIGIL REGUERA, Jose María, "Tradición asturiana de distinción: una aproximación al estudio de los grandes almacenes Botas”, en Liño. Revista Anual de Historia del Arte, Vol. 20, Universidad de Oviedo, 2014, pp. 109-124.

39 Plano firmado (diciembre de 1915) y solicitud de licencia (8 de enero de 1916) en AMO, 1-1-19-49. Puede verse una buena fotografía del edificio en el diario Región, Oviedo, 3-I-1928, donde destaca sobre el chaflán el nombre de Conrado B. Fontela acompañado de un gran caduceo, clara referencia a la función comercial. gran nave alargada con entrada en chaflán y vanos con lejanos resabios modernistas; en 1918 el almacén ya se encontraba en funcionamiento, junto a la tienda al detall-sastrería que los Fontela regentaban por entonces en el bajo del cercano $n^{0} 38$ de la calle Uría ${ }^{40}$. En Gijón sirve de ejemplo el comercio denominado Las Camelias: inaugurado en julio de 1911, este establecimiento de sedería, tejidos y novedades ocupaba la esquina entre las calles San Bernardo y Jovellanos ${ }^{41}$, formando parte

Esta obra también es recogida en GONZÁLEZ ROMERO, José Fernando, Arquitectura industrial de Oviedo, opus cit., pp. 101-102.

40 Ver el extenso y bien ilustrado reportaje que se les dedica en El Debate, Madrid, 21-VIII-1918. Como señal de su potencia, señalaremos que los Almacenes Fontela contaban en 1920 con una flamante instalación eléctrica supervisada por Juan Fríes, taller que también trabajaba para el Teatro Campoamor y el Banco Asturiano. El Debate, Madrid, 13-VIII-1920.

${ }_{41}$ "En las primeras horas de la noche de ayer, hemos visto en los escaparates de la nueva tienda de sedería, tejidos y novedades "Las Camelias" una elegante exposición de las más altas novedades para la actual temporada. Esta casa abrirá hoy sus puertas al público y le auguramos buen éxito [...]". En El Noroeste, Gijón, 3-VII-1911. 
de un extenso bloque en planta baja. Exteriormente el edificio presentaba una sencilla articulación de vanos rematados por molduras de arco rebajado, con limitado valor decorativo. En mayo de 1925 se anunciaba la inminente reforma del local en el chaflán, que sufragaría su nuevo propietario Valentín Benavente ${ }^{42}$ : la intervención, proyectada por Miguel García de la Cruz, consistió en la monumentalización de sus fachadas mediante la disposición de un orden columnario y la apertura de amplios escaparates $^{43}$. En noviembre del mismo año el comercio reabría sus puertas bajo el sugestivo nombre de La Innovación ${ }^{44}$.

Hablaremos ahora del Bazar Piquero de Gijón ${ }^{45}$ y del Gran Salón Bazar Masaveu de Oviedo, dos comercios de elevada popularidad -quizá los de mayor renombre entre sus competidores- que se caracterizaron por ofrecer una asombrosa cantidad de productos de dispar origen, uso y calidad, de modo un tanto

Un anuncio de 1912 demuestra que la tienda ya ocupaba entonces la esquina entre San Bernardo y Jovellanos. El Noroeste, Gijón, 13-X-1912.

42 "Valentín Benavente participa al público haber adquirido el comercio titulado "Las Camelias». Próximamente se abrirá con una verdadera liquidación de las actuales existencias por reforma de local". El Noroeste, Gijón, 16-V-1925.

43 Tramitación y proyecto en AMG, expediente 296/1925. En dicho documento Valentín Benavente solicita, en mayo de 1925, permiso municipal para reformar la fachada del comercio Las Camelias en la esquina San Bernardo-Jovellanos. El preceptivo informe facultativo dio el visto bueno al proyecto al considerar que las obras mejorarían " [...] notablemente las condiciones de ornato de las fachadas [...]". Este almacén, que no se conserva, es citado en la exhaustiva publicación de BLANCO GONZÁLEZ, Héctor, Miguel García de la Cruz, Arquitecto, Fundación Alvargonzález, Gijón, 2000, pp. 72 y 180.

44 "Por fin me es grato comunicarle, que habiéndose terminado la reforma en el local que adquirí en San Bernardo, 71 (esquina á Jovellanos), le abriré nuevamente al público el día 2 de Noviembre. Este establecimiento, que se titulará LA INNOVACIÓN se dedicará a la venta de novedades para señora, pañería, géneros de punto y tejidos en general. Valentín Benavente". El Noroeste, Gijón, 25-X-1925. Meses después un entusiasta reportaje en prensa señalaba: "Después de las grandes reformas que de poco tiempo a esta parte sufrieron nuestros principales comercios, equiparándolos a los de capitales europeas, era verdaderamente difícil abrir uno nuevo sin temer a las comparaciones, y Valentín Benavente se ha excedido y supo presentar en la calle de San Bernardo, esquina a la de Jovellanos, no solo un almacén de sedas y tejidos en competencia con cualquier otro, sino de una vistosidad única en su exterior [...]". El Noroeste, Gijón, 25-VIII-1926.

45 A este negocio le dedica unas páginas ADÚRIZ PÉREZ, Patricio, Crónica de la calle Corrida, Silverio Cañada Editor, Gijón, 1990, pp. 77-86. anárquico y apabullante: el elenco de mercancías abarcaba desde la quincalla más burda hasta los muebles más distinguidos, bibelots y figuritas decorativas, lámparas, material de escritorio y oficina, perfumes, bisutería, juguetes, artículos de viaje, cubiertos, cristalería, vajillas, enseres, paraguas, pianos, gramófonos...etc. ${ }^{46}$.

Hemos documentado la existencia del gijonés Bazar de Benigno Piquero Olay en una fecha tan lejana como octubre de 1877, momento en que el negocio ya ocupaba un bajo en la zona conocida como los Cuatro Cantones ${ }^{47}$; meses más tarde, Piquero solicitaba permiso para "[...] colocar un toldo para preservar su establecimiento núm. ${ }^{\circ} 24$ de la calle de la Trinidad de la influencia del sol y de los calores" ${ }^{48}$, dato que confirma una ubicación que se mantendría durante décadas. Desde los primeros tiempos Benigno Piquero se preocupó por adecentar su establecimiento, constándonos una temprana reforma en $1879^{49}$; con posterioridad, el negocio -que compartía edificio con el Hotel La Iberia- ${ }^{50}$ seguiría experimentando cambios, como la conversión en 1909 de ocho puertas del local en escapara-

46 Por supuesto, las premisas de renovación aprendidas del gran almacén -que ya señalamos para el comercio de telas y modas- también serían asumidas por estos bazares, que a la libre entrada o el etiquetado sumarian una dosis de artificio y pomposidad mediante la presentación de sus productos en largas hileras de aparadores, vitrinas y estantes, dentro de entornos ricamente iluminados y decorados con espejos, techos de escayolas, etc.

47 "Almacén de quincalla de Benigno Piquero. Cuatro Cantones. - Gijón. El dueño de este almacén ofrece al público un bonito surtido de juegos de café y chocolate, porcelana de Limoges, hules y gutaperchas de los gustos más caprichosos; juegos de bandejas inglesas con incrustaciones, baterías de cocina, cubiertos y cuchillos de todas clases, así como en bisutería, perfumería y juguetería, los artículos de la más alta novedad". En La Opinión, Gijón, 7-X-1877.

48 AMG, Libro de Actas de 1878, sesión ordinaria del 20 de julio, folio 287.

$49 \quad$ "En el número anterior de nuestro periódico nos hemos ocupado del establecimiento de ropas de D. Evaristo Noval, y dentro de pocos días tendremos que hacerlo del de quincallería, propiedad de nuestro amigo Benigno Piquero. La reforma que dicho Sr. hace en su casa, le dará más elegancia, y no dudamos que los distintos artículos que allí se venden, ofrecerán más atractivo a la humanidad doliente, que al cruzar por los Cuatro-Cantones, lo hará sin querer entre Scila y Caribdis". En La Opinión, Gijón, 15-VI-1879.

50 SUÁREZ BOTAS, Gracia, Hoteles de viajeros en Asturias, opus cit., pp. 350-351. 
tes, operación muy habitual ${ }^{51}$. A finales del s. XIX el Bazar Piquero ofrecía a los gijoneses y "á todos los forasteros" la posibilidad de deleitarse con las numerosas existencias que llenaban su comercio en los Cuatro Cantones así como su Salón Exposición, instalado en la calle Rastro (Linares Rivas), $\mathrm{n}^{\circ} 16^{52}$ : gracias a testimonios gráficos conocemos el aspecto de dichos locales ${ }^{53}$, siendo posible vislumbrar una estética acumulativa -cierta celebración de la profusión- típicamente decimonónica, heredera de las exposiciones científico-técnicas, industriales y artísticas tan en boga por

51 "Don Benigno Piquero y Olay, vecino de esta villa [...] expone: Que desea convertir ocho puertas en escaparates en la casa $n^{\circ} 24$ de la calle de la Trinidad, todo con arreglo al diseño que se acompaña por lo que suplica se le conceda el oportuno permiso". La autorización fue concedida el 18 de diciembre de 1909. AMG, expediente 322/1909. Héctor Blanco señala para el ámbito gijonés: "Hasta la década de 1890 no aparece un elemento que hoy resulta inherente a todo inmueble urbano: la configuración como local comercial de la planta baja, donde el escaparate va a convertirse en un elemento esencial y distintivo. Sólo en los inmuebles construidos próximos al cambio de siglo va a preverse esta necesidad de uso, mediante la traza de la planta inferior con amplios vanos, por lo que va a ser constante la reforma del caserío preexistente. Con este fin, durante la primera década de este siglo, se va a optar por tres soluciones: la conversión de alguna de las puertas de acceso de la planta terrena en escaparates, la colocación de vitrinas colgadas en los muros exteriores, que era preceptivo instalar y retirar a diario, o bien la apertura de huecos en la fachada". BLANCO GONZÁLEZ, Héctor, Miguel García de la Cruz, opus cit., pp. 70-71.

52 En 1897 Benigno Piquero explicaba: “Si mi ánimo fuera molestar la atención de mis apreciabilísimos lectores, nada más fácil que enumerar los objetos que expongo en mi Salón, Rastro, 16 (entrada pública); pero me llevaría muchos días [...] No siendo, pues, mi intención molestar á ustedes, creo lo más oportuno ceñirme á relatar lo que últimamente he recibido, con la advertencia de que lo que aquí callo, también lo tengo, pues que esta casa es una especie de Caja de Pandora, pero sin nada malo [...] Decía, señores forasteros, que Gijón es una de las poblaciones más adelantadas de España, y para ello me fijaba en lo que encierra mi Establecimiento (Cuatro Cantones) ó mi Salón Exposición (Rastro, 16)". Ver anuncio completo en El Noroeste, Gijón, 15-VIII-1897, número extraordinario.

53 Ver el Programa de los Festejos con que el Ilustre Ayuntamiento y el Pueblo de Gijón se proponen obsequiar a los bañistas durante el verano de 1888, Imp. de A. Blanco, Gijón, 1888, donde ya consta la existencia del Salón Exposición en la calle Rastro, 16. Más imágenes en: Centenario de Jovellanos. Gijón. 1911, Imp. Jose Blass y Cía., Madrid, 1911; NAVA VALDÉS, Antonio, Turismo Asturias (Guia para el turista), opus cit.; ÁLVAREZ Y ÁLVAREZ, B. (dir.), Guía Industrial y Artística de Asturias, Ed. Hispánica, Bilbao, agosto de 1924. entonces $^{54}$. Tras la muerte de Benigno Piquero 81 Olay en $1923^{55}$, la sociedad Benigno Piquero y Compañía se disolvería ${ }^{56}$ y la tienda de Cuatro Cantones quedaría en manos de la firma Muebles y Decoraciones Artísticas S.A. García y Escobedo ${ }^{57}$; por su parte, el Bazar Piquero

54 Celeste Olalquiaga apunta, en relación al pionero Crystal Palace de Londres (1851): "Siguiendo el paradigma de los pasajes [...] el Palacio de Cristal era una gigantesca estructura de hierro y vidrio dedicada a una nueva manera de mirar, la del consumidor potencial. Tanto por su desenfadado énfasis en la exposición, la proliferación y el artificio, como por las proporciones globales de su alcance de feria comercial, el Palacio de Cristal prácticamente inauguró la era moderna tal y como la conocemos hoy en día”. OLALQUIAGA, Celeste, El reino artificial. Sobre la experiencia kitsch, Gustavo Gili, Barcelona, 2007, pp. 29-30. Las icónicas exposiciones universales parisinas son tratadas por AGEORGES, Sylvain, Sur les traces des Expositions Universelles. À la recherche des pavillons et des monuments oubliés, $\mathrm{Pa}$ rigramme, Paris, 2006. La Exposición Regional de 1899 constituye un buen ejemplo a nivel local de esta clase de eventos. Ver ANES ÁLVAREZ DE CASTRILLÓN, Rafael, "La Exposición Regional de 1899" en Boletín del Real Instituto de Estudios Asturianos, Año 53, № 153, Oviedo, 1999, pp. 159-176. Ver igualmente El Noroeste, Gijón, días 23, 24 y 25-VII-1899.

55 El propietario y alma del bazar, el popular Benigno Piquero Olay, fallecía en Gijón el 2 de abril de 1923 a los 74 años de edad. Esquela y crónica de su muerte en $E l$ Noroeste, Gijón, 3-IV-1923.

56 "Doña María Alonso y Bonet, mayor de edad, viuda, vecina de Gijón, por sí y como representante legal de sus hijos Doña María del Rosario y don Benigno Piquero Alonso [...] representando toda la participación, derechos y acciones de don Benigno Piquero Olay, en la sociedad colectiva "Benigno Piquero y Compañía", inscrita en el precedente asiento, y don Gerardo García Alonso y don Valentín Escobedo y González-Carbajal, este soltero y aquél casado, mayores de edad, vecinos de dicha villa, a requerimiento de estos dos últimos en uso del derecho que les confiere la base segunda del contrato social, declaran disuelta y terminada la expresada sociedad "Benigno Piquero y Compañía” retrotrayendo los efectos de esta declaración al día primero de Mayo de mil novecientos veinticuatro; y solicitan que se haga constar la disolución en este Registro Mercantil [...]”. Registro Mercantil de Asturias, Libro de Sociedades, tomo 19, hoja 833, folio 139, inscripción 2a.

57 Sobre Muebles y Decoraciones Artísticas S.A., sociedad de García y Escobedo, véase el anuncio en Deporte y Turismo Astur. Verano de 1925, Año IV, Ed. La Fe, Gijón, 1925, donde se explica: “La antigua razón social B. Piquero y C.a, es hoy la potente Sociedad Anónima MUEBLES Y DECORACIONES ARTÍSTICAS GARCÍA Y ESCOBEDO, que demostrando un sentido comercial agudísimo, ha extendido sus negocios por España entera [...] El soberbio Bazar gijonés, una de las más atrayentes y vistosas notas de nuestro bulevar, centro de reunión de las más distinguidas clases sociales, según noticias que hemos adquirido, muy pronto será aumentado con nuevos salones y dependencias en el piso principal del soberbio 
resurgiría poco tiempo después en los números 86-88 de la calle Corrida ${ }^{58}$.

A pesar de su prestigio, impronta arquitectónica e influencia en la vida comercial y artística de la capital asturiana ${ }^{59}$, el Gran Salón Bazar Masaveu, enclavado en el corazón de Oviedo, sigue siendo en buena medida un desconocido. En junio de 1902, sin duda deseando extender sus actividades mercantiles, los Masaveu estrenaban un refinado Salón-Exposición a modo de bazar en los bajos de un bloque contiguo al edificio erigido por Javier Aguirre ${ }^{60}$. Este primer salón se vería superado, apenas dos años más tarde, por un empeño mucho más notable, y la tarde del sábado, 9 de julio de 1904, los ovetenses asistirían con asombro a la apertura del Gran Salón Bazar, situado frente al almacén de tejidos y oficina bancaria de los Masaveu en la acera opuesta de la calle Cimadevilla ${ }^{61}$. El nuevo comercio había sido instalado en el lugar anteriormente ocupado por el Teatro Ovies, un pequeño coliseo de fugaz existencia cuyas obras dirigió Luis Bellido ${ }^{62}$. No sabemos has-

edificio propiedad de la Empresa”. Dicha ampliación se ejecutaría, apareciendo reproducida en imágenes en Región, Oviedo, 4-IX-1926.

58 El refundado Bazar Piquero sería dirigido inicialmente por María del Rosario Alonso Bonet, viuda de Benigno Piquero Valle, a su vez hijo de Benigno Piquero Olay. Ver anuncios y fotografías en Gijón Veraniego. 1927, año XIV, Imprenta Comercial Covadonga, Gijón, 1927. Tal como informa la fuente citada, los interiores de la nueva tienda de Corrida fueron decorados por la conocida Casa Gargallo.

59 El uso de los espacios comerciales como escenario de exposiciones artísticas es tratado por TIELVE GARCÍA, Natalia, Pintura contemporánea en Asturias. Su trama entre 1898 y 1936, Trea, Cenero (Gijón), 2005, pp. 4452. Por citar dos casos relevantes ligados al Gran Salón Bazar, en mayo de 1906 el pintor Tomás García Sampedro exhibía en sus escaparates el cuadro titulado "La entrada de mi estudio” (El Noroeste, Gijón, 18-V-1906), y en enero de 1919, Evaristo Valle protagonizaba una exposición monográfica dispuesta en los salones del establecimiento (El Noroeste, Gijón, 17-I-1919).

60 Una minuciosa descripción del Salón-Exposición Masaveu en El Correo de Asturias, Oviedo, 24-VI-1902.

${ }_{61}$ Crónicas de apertura en El Correo de Asturias, Oviedo, 10-VII-1904 y El Carbayón, Oviedo, 11-VII-1904.

62 "La dirección técnica del nuevo teatro, como saben nuestros lectores, ha estado á cargo del ilustrado arquitecto diocesano señor Bellido [...]". El Correo de Asturias, Oviedo, 19-V-1899. "El público que anoche visitó el teatro de Cimadevilla felicitó al director de las obras, distinguido arquitecto señor Bellido". El Carbayón, Oviedo, misma fecha. No sería descabellado pensar que el propio Bellido fuera autor de la traza. El Teatro Ovies fue inaugurado en mayo de 1899 por iniciativa del empresario Gregorio Ovies. Ver crónica en El Noroeste, Gijón, 26-V-1899. Consúltese el artículo firmado por ta qué punto el Bazar Masaveu aprovechó la estructura preexistente del Teatro Ovies, pero sí nos consta que las obras de adaptación del mismo para la nueva función comercial fueron dirigidas por Juan Miguel de la Guardia ${ }^{63}$. Las crónicas de la inauguración del Bazar Masaveu describen un interior magnífico, amplio y luminoso, con elevados techos, organizado en vestíbulo y patio principal; una escalera situada a la entrada conducía desde la planta de calle a unas galerías altas, que circundaban la sala central ${ }^{64}$.

Un aspecto característico del Gran Salón Bazar sería su doble fachada a las calles Cimadevilla y del Peso, cualidad heredada del propio Teatro Ovies, que ya contaba con acceso por ambas calles, en el caso del Peso precedido por un jardín ${ }^{65}$. Tradicionalmente se ha venido considerando que ambas fachadas, que aún se conservan, habrían sido realizadas entre 19101915, atribuyéndose su autoría -al menos parcialmente- a Julio Galán Carvajal ${ }^{66}$. Teniendo

CONDE, Ernesto, "La corta vida del teatro Ovies", en La Nueva España, Oviedo, 20-VIII-1985. Ver también DE LA MADRID ÁLVAREZ, Juan Carlos, Cinematógrafo y "varietés" en Asturias (1896-1915), Servicio de Publicaciones del Principado de Asturias, Oviedo, 1996, pp. 324-326.

${ }_{63}$ "Las obras que convirtieron el antiguo Teatro Ovies en un Gran Salón Bazar, las dirigió el arquitecto Sr. Laguardia: con eso solo, quedan ya elogiadas". El Carbayón, Oviedo, 11-VII-1904.

64 Una infinidad de productos a la venta se disponía sobre estanterías con fondo de espejo o vitrinas de cristal y níquel, y todo el interior se beneficiaba de la luz natural que penetraba a través de una vidriera cenital y de los vanos abiertos en la fachada de Cimadevilla y en el fondo del local. Puede verse una estupenda imagen del interior del Bazar en su primera época en Blanco y Negro, Madrid, Año XVIII, Núm. 908, 26-IX-1908, p. 26.

65 "Hay numerosos cuartos para artistas, y desde luego asegurarnos que cuantas condiciones pudieran pedirse para comodidad del público reúne este local pues cuenta también con dos entradas (por las calles de Cimadevilla y Peso) y con un extenso jardín, que seguramente habrá de utilizar el público, sobre todo en la época de primavera y verano." El Correo de Asturias, Oviedo, $19-\mathrm{V}-1899$.

${ }_{66} \mathrm{M}^{\mathrm{a}}$ Cruz Morales escribe al respecto: "Muchos años después, entre 1910 y 1915 y en el número 15 de la misma calle Cimadevilla y con fachada también a Peso, la firma inaugurará el Bazar Masaveu. Aprovechando el antiguo teatro Ovies, con amplias cristaleras, fisonomía modernista, y cosmopolita, esta tienda tuvo un rotundo éxito [...]". En MORALES SARO, Ma Cruz, "La Casa Masaveu y el arquitecto Javier Aguirre”, opus cit., p. 71. La misma autora, en una revisión de la obra de Julio Galán Carvajal, señala: "Otra obra singular fueron los Almacenes Masaveu (1910-1915). Para la misma empresa propietaria de la casa de igual nombre en 

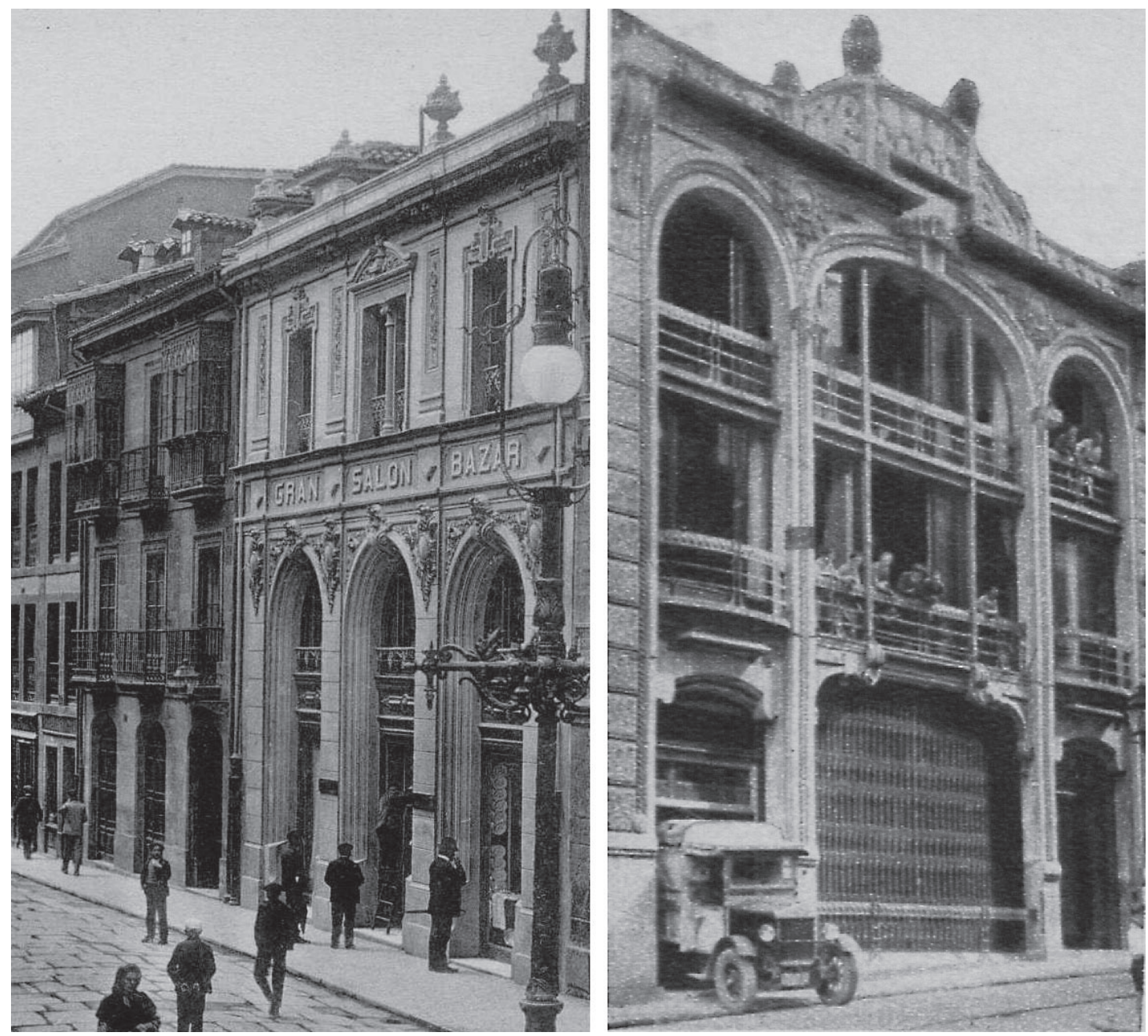

Fig. 5. Gran Salón Bazar Masaveu (Oviedo). Izquierda: fachada a la calle Cimadevilla. Fuente: detalle de postal de Hauser y Menet, ca. 1905. Muséu del Pueblu d'Asturies. Derecha: fachada a la calle del Peso, en un anuncio de Ceñal y Zaloña de 1933. Fuente: revista Blanco $y$ Negro, Madrid, Núm. 2.213, 12-XI-1933. Colección particular.

en cuenta que el Bazar llevaba en activo desde 1904 y que existen diferencias sustanciales de estilo entre ambas fachadas, nos atrevemos a sugerir, de forma provisional y a riesgo de

Cimadevilla, y frente al edificio de Javier Aguirre citado, se desea ahora un almacén moderno, vistoso, de corte parisino [...] El arquitecto, en la fachada a la calle de El Peso, concibe amplias cristaleras, enmarcadas por tres arcos que unifican todas las alturas [...]". En MORALES SARO, Ma Cruz, "Julio Galán Carvajal”, opus cit., p. 290. En la misma línea, ver CUESTA RODRÍGUEZ, Ma José et al., Guía de arquitectura y urbanismo de la ciudad de Oviedo, Colegio Oficial de Arquitectos de Asturias, Oviedo, 1998, p. 139. En su correspondiente ficha del vigente Catálogo Urbanístico del Concejo de Oviedo, el edificio aparece bajo la denominación "Cimadevilla, 15/Peso, 12. Almacenes Masaveu" (ref. 158), atribuido una vez más a Julio Galán Carvajal, 1910-1915. equivocarnos, una explicación alternativa más precisa. En nuestra opinión, la fachada que hoy pervive en la calle Cimadevilla $\mathrm{n}^{\circ} 15$ se correspondería con los primeros años de funcionamiento del Bazar y pertenecería al frontispicio del desaparecido Teatro Ovies, aunque habría experimentado algunos cambios pues nos consta que fue reformada en 1902, cuando la finca se encontraba ya en manos de los Masaveu $^{67}$; de este modo, tanto Luis Bellido como

67 "A instancias de D. Pedro Masaveu y de conformidad con lo propuesto por el Arquitecto y Comisión de policía urbana se le concedió licencia para reformar la fachada de la casa $n^{\circ} 17$ de la Calle de Cimadevilla con sujeción al plano al efecto presentado [...]". AM0, Libro de Actas de 1902, sesión ordinaria del 14 de enero, folio 8. Por aquel entonces a la finca le correspondía el número 17, pasando a ser el 15 más adelante. Un 
Juan Miguel de la Guardia podrían compartir la autoría de la misma, actuando en fases sucesivas: su estilo mixto, a caballo entre un neobarroco tardío y cierto modernismo larvado, avalaría este planteamiento. Por el contrario, la fachada de la calle del Peso, compuesta en un lenguaje abiertamente modernista, con estructura metálica, amplios vanos y bellos detalles decorativos en estilizada clave nouveau, es probablemente fruto de una reforma y ampliación del Bazar que tuvo lugar entre 1916 y $1918^{68}$. Para esta fachada $-\mathrm{y}$ la adecuación interior llevada a cabo paralelamente- ${ }^{69}$ no ve-

año más tarde los Masaveu recibían “autorización para levantar la acera que existe en la línea de fachada de la casa $n^{\circ} 17$ de la calle de Cimadevilla y sustituirla por otra de cemento Portland [...]". AMO, Libro de Actas de 1903, sesión ordinaria del 13 de marzo, folio 24 .

68 En marzo de 1916 se inician los trámites para levantar un edificio en la zona correspondiente a la fachada del Peso: "Entrando en el despacho de asuntos se dio cuenta de una instancia de D. Francisco González Berbeo solicitando autorización para derribar la muralla y desmontar el terreno en la parte del solar correspondiente al Bazar Masaveu que tiene acceso a la calle del Peso y construir al propio tiempo un edificio en dicho solar [...] de conformidad con lo propuesto por el Sr. Arquitecto y Comisión se acordó acceder a lo solicitado [...]". AMO, Libro de Actas de 1916, sesión ordinaria del 24 de marzo, folio 62. F. González Berbeo aparece citado como contratista de obras en Arquitectura y Construcción. 1917. Resumen Anual de Arquitectura, Bellas Artes, Ingeniería, Decoración e Industrias Constructivas, asi en España como en el extranjero. Libro del arquitecto y del constructor. Anuario de la Construcción para 1918, Vega y March, Barcelona, 1917, Libro Segundo, Secciones técnica e indicadora clasificadas por provincias, p. 290. La autorización municipal aparece publicada en el Boletín Oficial de la Provincia de Oviedo, no 158, 12-VII-1916, p. 5. Unos meses después, en octubre del 1916, Elías Masaveu exponía a la corporación municipal: "El que subscribe, propietario y vecino de Oviedo [...] expone: Que proyecta dar salida á las Aguas del Edificio que construye en la calle del Peso, á cuyo efecto solicita de V.S. la correspondiente autorización para acometer la alcantarilla general de la Calle [...]". Ver AMO, 1-1-47-27. Finalmente, en el Registro de la Propiedad n ${ }^{\circ} 3$ de Oviedo, tomo 935, libro 386, folio 50, $8^{\text {a }}$ inscripción (24-IV-1933) se describe "Un edificio sito en Oviedo, entre las calles de Cimadevilla, por la que tiene el número quince moderno, antes el diecisiete; y la del Peso, por la que corresponde el número doce; compuesto de bajo y dos pisos, re-edificado a expensas de la Sociedad "Masaveu y Compañía" en el año de mil novecientos dieciocho sobre el terreno que ocupaban una casa, almacenes, un patio y una huerta [...]".

69 La nueva fachada del Peso vendría acompañada de una intervención en el interior del Bazar cuyo alcance nos resulta difícil precisar. Al menos en la zona más próxima a la calle del Peso se compuso una crujía de varias alturas y planta claustral, con estructura de finos soportes de hierro, barandillas de tracería metálica y mos inconveniente en mantener la atribución a Julio Galán Carvajal, a falta de datos concluyentes $^{70}$; igualmente parece oportuno señalar, respecto a la fachada de la calle del Peso, el intento por lograr una cierta desmaterialización con una solución que recuerda a la de los grandes almacenes L'Innovation de Bruselas (1901), obra de Victor Horta ${ }^{71}$. A mediados de la década de 1920, quizá debido al desplazamiento de la actividad comercial hacia el barrio de Uría, se barajó la posibilidad de trasladar el Bazar Masaveu a dicha zona y dedicar el edificio de Cimadevilla-Peso a cinematógrafo ${ }^{72}$, pero esta opción no prosperaría. Finalmente, entrada la década de 1930 se producía el cierre de tan emblemático comercio $^{73}$.

balcones curvos. Desconocemos si el resto del Bazar fue modificado según el mismo criterio. Ver imagen del interior reformado en la revista España. Semanario de la vida nacional, Madrid, Año V, Núm. 224, 24-VII1919, p. 19. Otra imagen desde un ángulo diferente en Blanco y Negro, Madrid, Año 43, Núm. 2.213, 12-XI1933, p. 173.

70 No hemos localizado alusión alguna a este proyecto en el catálogo del Archivo de Julio Galán Carvajal.

${ }^{71}$ Amplíese esta cuestión con SERRANO SÁSETA, Rafael, "Los orígenes comerciales del fenómeno de la desmaterialización de la fachada en la arquitectura moderna. Transparencia y luz eléctrica”, en REIA. Revista Europea de Investigación en Arquitectura, \#02, Universidad Europea de Madrid, 2014, pp. 163-180, especialmente las pp. 172-173.

72 “ ¿Se va a instalar un cine en Cimadevilla? [...] Entre tanto tenemos noticia de otro nuevo proyecto; parece ser que éste es un poco más positivo: de un gran cine. Se establecerá en los salones que actualmente ocupa el bazar Masaveu, sitio de una gran estrategia para sala de espectáculos, porque tiene acceso por dos calles. El bazar no desaparecerá, sino que será instalado en el local que actualmente ocupa la Brasserie, en la calle de Uría”. En Región, Oviedo, 4-XI-1926.

73 "¿Se cierra el Bazar de Masaveu? Se nos asegura que han sido avisados los empleados del Bazar Masaveu, establecido en Cimadevilla, por supresión de la industria. Con esta determinación de la Casa Masaveu, quedan en la calle más de veinte obreros del mostrador". En El Noroeste, Gijón, 27-I-1933. Tras el cierre, su lugar fue ocupado inmediatamente por los almacenes de droguería Ceñal y Zaloña: "Una gran firma comercial asturiana. La sociedad anónima Ceñal y Zaloña. Constituida esta Compañía en Oviedo en el mes de enero de este año, tiene, sin embargo, el prestigio de las viejas firmas [...] Precisamente en estos días ha inaugurado esta entidad el soberbio edificio de Cimadevilla 15, adquirido para el perfecto desenvolvimiento de sus negocios". Ver Blanco y Negro, Madrid, Año 43, Núm. 2.213, 12-XI-1933, p. 173. En la década de 1970 una reforma dio nueva distribución al edificio, manteniendo las consabidas fachadas. Ver AMO, expediente 2262/74. 
Llegados a este punto, parece evidente que entre las últimas décadas del s. XIX y el primer tercio del XX, Gijón y Oviedo sirvieron de escenario a un proceso de actualización de sus respectivas estructuras comerciales que se manifestó de forma especialmente elocuente en los establecimientos de tejidos, novedades y modas, así como en los bazares. Dichos comercios, sin duda inspirados por los magníficos referentes en auge más allá de las tierras asturianas, incorporaron nuevas formas de vender y nuevas formas de exhibir, que en ocasiones vinieron acompañadas de interesantes empeños arquitectónicos de diverso calado: a veces, la mera sustitución de una vieja puerta por un sofisticado escaparate ${ }^{74}$; en otros casos, la adecuación o construcción de edificios de cierta envergadura. En el arranque de la década de 1930, tal vez creyéndose a la altura de París, Berlín o Nueva York, los Almacenes Al Pelayo de Oviedo se presentaban -de forma tan chocante como exagerada- como "la catedral de las confecciones" 75 , expresión que a pesar de su ingenuidad refleja perfectamente la asimilación e intento de reproducción local de los modelos y esquemas de consumo de la Modernidad, mayoritariamente dirigidos a todos los estratos sociales y muy particularmente al público femenino ${ }^{76}$. Tras la Guerra Civil, durante la larga dictadura franquista, el gran almacén alcanzaría en Asturias la plena madurez.

75 Ver anuncio en La Voz de Asturias, Oviedo, 2-XI-1930.

76 Los mensajes democratizadores en la publicidad durante el período estudiado son bastante frecuentes, insistiendo en la capacidad de los comercios modernos para satisfacer por igual las demandas de toda clase de clientes, sin importar su procedencia ni riqueza. Como muestra, citaremos tres fragmentos extraídos de anuncios: "La casa de Masaveu y Compañía [...] Allí, de contínuo, se congregan las damas gijonesas, las señoritas distinguidas y la alegre y simpática modistilla a hacer provisiones de moda." (Casa Masaveu, en Gijón Veraniego. 1920, opus cit.); “Almacenes La Sirena [...] Lo difícil es adquirir estas creaciones a precios afinados para que estén al alcance de todas las fortunas. Nuestros ALMACENES, deseando que todos sus clientes puedan participar de los tejidos de gran moda, sacrifica todas las utilidades y vende a precios de fábrica las telas empleadas por los grandes modistos" (Almacenes La Sirena, en Acción: defensor de los intereses de la mujer, Gijón, 7-V-1932); "El Obrero. El Empleado. El Rentista. El Burgués. El Elegante y El Artista. Todos compran sus calzados en LA EXPOSICIÓN (Cuatro Cantones) porque es donde encuentran mayor surtido, mejores clases y precios más económicos" (Calzados La Exposición, en El Noroeste, Gijón, 22-VI-1935). 
